\title{
Simulation Study to Develop Reactivity Control Compression-Ignition Engine (RCCI)
}

Nguyen Ngoc Dung ${ }^{*}$

Ho Chi Minh City University of Food Industry Vietnam

DOI: $10.36347 /$ sjet.2020.v08i07.002

| Received: 01.07.2020 | Accepted: 10.07.2020 | Published: 16.07.2020

*Corresponding author: Nguyen Ngoc Dung

Abstract

The study of reactivity-controlled compression-ignition (RCCI) engine is one of the most important concepts introducing to diesel engine owing to reduce exhaust gas emission. The main objective of this research is to study developing RCCI engine in Vietnam based on simulation. AVL MCC model and Woschni model in AVL Boost software are used to simulated engine combustion and performance characteristics. The result showed that RCCI engine illustrated better combustion process than conventional diesel engine, which increased engine performance and decreased $\mathrm{NO}_{\mathrm{x}}$ and soot emissions. The study has contribution to the research and development of RCCI engine in Vietnam.

Keywords: Engine simulation, RCCI engine, direct-injection diesel engine, emission, AVL MCC.

Copyright @ 2020: This is an open-access article distributed under the terms of the Creative Commons Attribution license which permits unrestricted use, distribution, and reproduction in any medium for non-commercial use (NonCommercial, or CC-BY-NC) provided the original author and source are credited.

\section{INTRODUCTION}

Internal combustion engine has over one hundred year's development and plays an important role in transportation, commercialization, and power generation. Currently, internal combustion engine is main energy source for home machinery (pump, generator, hand saw..), tractor, and approximately 750 million vehicles around the world [1-3]. In 2020, there were more than 75 million automobiles manufactured, increased $50 \%$ in comparison with previous decade. One of the main reasons for its development is the increase of China market. The automobile market is a quarter of world share market. One-third of world automobiles were produced by European country, in which diesel engines with the advantages in performance, fuel economics are used in a haft.

With a huge amount of engine manufacturing every year, the research of gasoline and diesel engine with a small innovation or modification on engine performance will have big influences to the environment and economics. World energy consumption is about 86 million barrels of fossil fuel, in which $70 \%$ is applying for internal combustion engine. The using of fossil fuel cause an increase of pollutant such as $\mathrm{NO}_{\mathrm{x}}$, soot, $\mathrm{CO}_{2}$...In average, the application of fossil fuel emitted 37 billion tons of $\mathrm{CO}_{2}$, which contributes a huge greenhouse gas to the environment and causes climate change. Air pollution have strong affected to the environment, people healthcare and other [4-6]. By this reason, many countries have been developed and applied stricter emission regulation and standard in order to limit the engine emission [6,7]. Improving fuel efficiency is one of the most promising solutions to reduce the greenhouse gas.

However, internal combustion engine may still popular and play an important role for the next 50 years owing to its advantages in energy density, easy to use...Many researchers focus on improving fuel efficiency, fuel economic and reducing engine emissions [5,8-10]. The applications of hybrid and electric car are promising; however, it is difficult in applying for high load vehicles with high demand in durability or the limitation of driving distance. Besides, efficiency of power generators is still low (less than $50 \%$ ) and loss during electric transmission causing low overall efficiency of hybrid and electric car.

Nowadays, with the development of technology, it is easy to apply computer simulation for engine research. There are many successful new engine models developing from simulation study. Low temperature combustion engine (LTC) helps increase engine thermal efficiency in comparison to diesel engine together with low combustion temperature, which tend to reduce and control NOx emission $[8,11-$ 13]. The LTC engine include HCCI engine 
(Homogeneous Charge Compression Ignition), PCCI (Premixed Charge Compression Ignition) [12]; and RCCI engine (Reactivity Controlled Compression Ignition).

HCCI engine is a combination of sparkignition and compression-ignition engine. HCCI can use gasoline, diesel and other alternative fuels $[14,15]$. Thermal efficiency of HCCI is slightly higher in comparison with gasoline engine. With homogeneously pre-mixed mixture and low temperature combustion, $\mathrm{NO}_{\mathrm{x}}$ and soot emissions from HCCI engine decrease dramatically. However, the limitation of HCCI is difficult to control start of combustion, in which it depended on engine temperature, its compression ratio, and mixture formation.

Premixed Charge Compression Ignition (PCCI) engine is another version of HCCI with improving control in start of combustion and emission management [12]. The start of injection time was controlled to manage combustion ignition process occurring in combustion chamber. Fuel combustion efficiency of PCCI engine is higher in comparison with HCCI engine. However, PCCI engine get difficulty in controlling and changing engine load.

RCCI engine is new development of LTC engine. RCCI engine uses two kinds of fuel and its combustion was controlled by reactivity of the fuels. The RCCI engine is directly controlling mixture ratio according to engine load and speed. The formation of engine NOx and soot may satisfy legislation without using engine post-treatment devices (SCR, EGR, DPF). The main objective this research is developed this engine model in Vietnam base on simulation. The RCCI engine was developed base on parameters and experiments from AVL 5042 engine

\section{AVL 5402 ENGINE MODEL}

AVL Boost software was used in this research to develop RCCI engine from AVL 5402 engine. The AVL 5402 engine was a direct-injection diesel engine with electronic controlled, which was designed for research only. Table 1 shows us specification of AVL 5402 engine.

Figure 1 demonstrates simulation model of AVL 5402 engine. Elements in model included 01 air filter (CL), 01 engine (E), 01 cylinder (C), 1 stabilizer tank (SB); 3 flow resistance elements (R), 7 connecting $\operatorname{rod}(1,2,3,4,5,6,7)$. Measurement point $\mathrm{R}$ in model was to measure volumetric efficiency, which generated flow parameters and intake temperature.
Table-1: AVL 5402 engine specification

\begin{tabular}{|l|l|}
\hline Parameter & Unit \\
\hline Number of cylinder & 1 \\
\hline Bore x stroke $(\mathrm{mm})$ & $85 \times 90$ \\
\hline Volume displacement $\left(\mathrm{V}_{\mathrm{h}}\right)\left(\mathrm{cm}^{3}\right)$ & 510,7 \\
\hline Compression ratio & 17,1 \\
\hline Max power $(\mathrm{kW})$ & 8 \\
\hline Max speed $(\mathrm{rpm})$ & 4200 \\
\hline Fuel system & Common Rail \\
\hline Number of injector hole & 5 \\
\hline Injector hole diameter & 0,17 \\
\hline Injection pressure & 800 \\
\hline Injection time & 20 \\
\hline
\end{tabular}

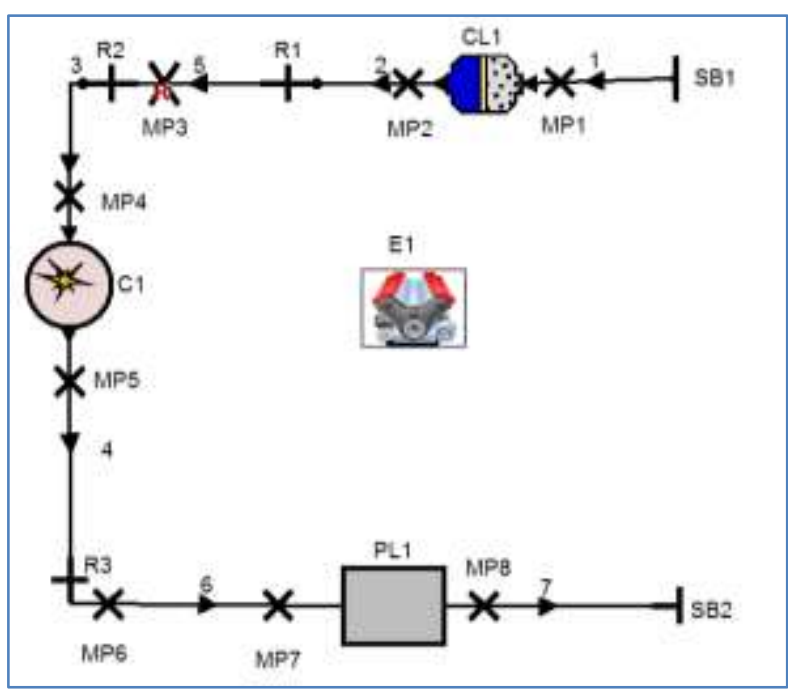

Fig-1: AVL 5402 engine simulation model

To validate simulation model of AVL 5402 engine, we have to calibrate its simulation result and experiment. Figure 2 and Figure 3 presented in-cylinder pressure result without and with fuel injection for experiment and simulation. The engine was operated at $2000 \mathrm{rpm}$ with injection pressure 800bar at $20 \mathrm{deg}$ BTDC. The results showed similar trend and value. Therefore, we could apply this model for other study.

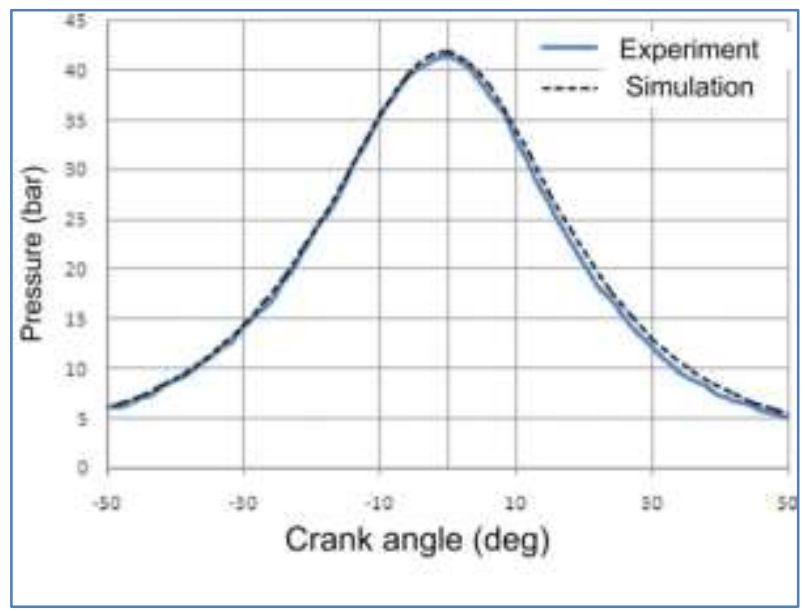

Fig-2: In-cylinder pressure without fuel injection 


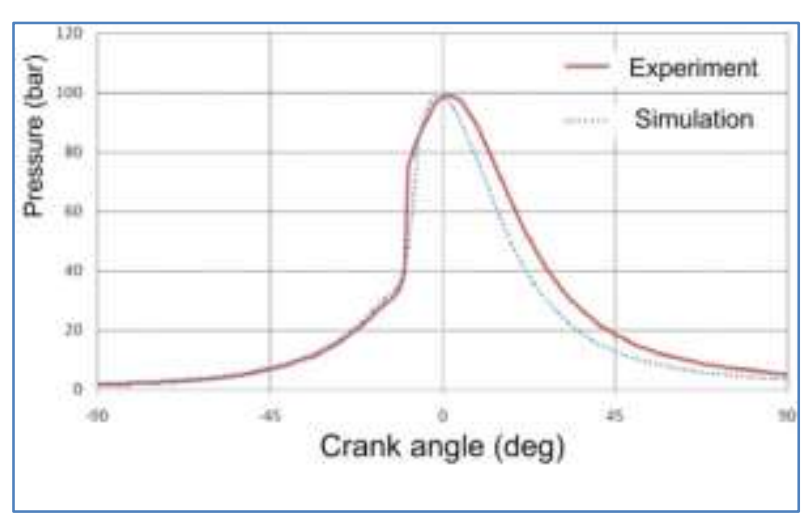

Fig-3: In-cylinder pressure with fuel injection

\section{RCCI ENGINE MODEL}

RCCI engine has two fuels system. RCCI model was built based on AVL 5402 model with cooperate gasoline model.

\section{Fuel system and combustion model}

Diesel engine is inhomogeneous engine with mixture formation in combustion chamber. AVL Boost does not simulate fuel system of diesel engine into solid elements. It controls these parameters through combustion model and heat transfer model.

In this research, AVL_MCC combustion model was used to simulation combustion process. The advantages of this model are we could easily to simulate diesel injectors, easily to control injection time and to control number of injection easily. Input parameters for simulation included amount of diesel fuel per stroke, number of injection hole, injector hole diameters, injection pressure, injector delay...

\section{RCCI model}

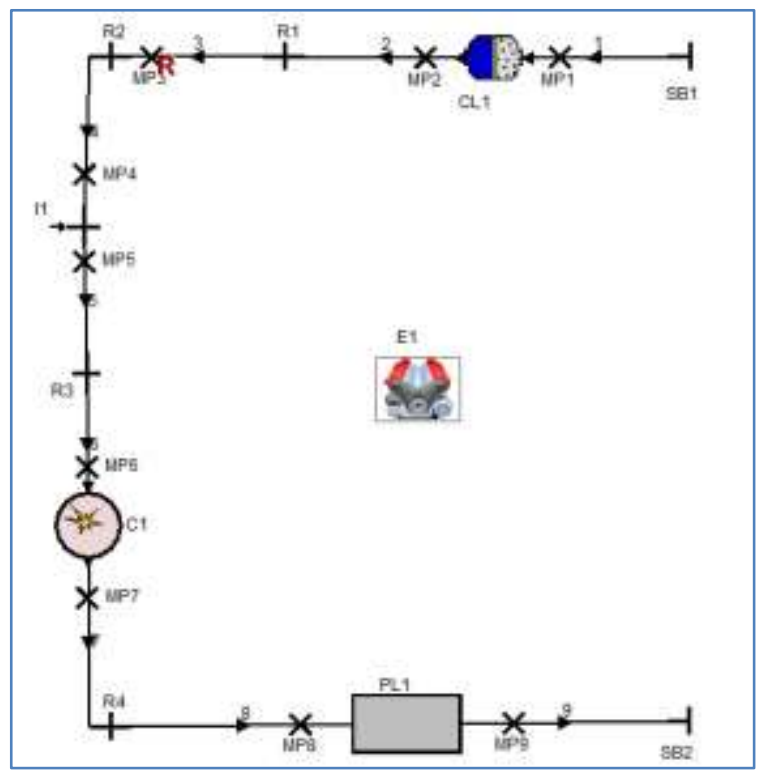

Fig-4: RCCI engine simulation model

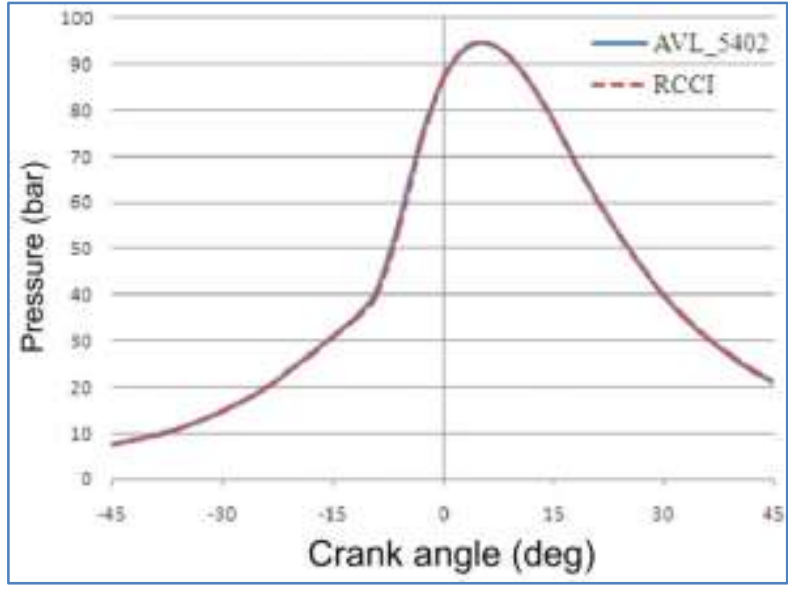

Fig-5: In-cylinder pressures

Figure 4 showed RCCI engine model. Elements in model included 01 air filter (CL1), 01 engine (E1), 01 cylinder (C1), 1 stabilizer tank (PL1); 01 gasoline injector (I1), 4 flow resistance elements (R), 9 connecting rod $(1,2,3,4,5,6,7)$. The model was validated by comparison simulation result (without gasoline injection) with experiment result of AVL 5402 at the same condition. Figure 5 showed similar result and value for the concern testing.

Simulation reci engine operate with gasoline injection, diesel injection 1 time (rcci_1)

Start of combustion in RCCI_1 engine is later in comparison with its in AVL 5402 engine. In RCCI_1 engine, maximum pressure occurred at $9 \mathrm{deg}$ ATDC, a little higher than AVL 5402 engine. However, overall thermal efficiency of RCCI_1 engine is lower than that of AVL 5402 engine owing to low energy release. The reason was suggested by the inhomogeneous between the fuels in which AVL 5402 engine used pure diesel fuel and RCCI_1 engine applied dual fuels (95\% diesel, $5 \%$ gasoline) (Figure 6). In Figure 7, NOx emission of RCCI_1 engine lower than that of AVL 5402 engine owing to its lower combustion temperature (see Figure 8 \& 9). Soot emission of RCCI_1 was also low and explained by better combustion.

Figure 8 and Figure 9 showed us combustion result between RCCI_1 and AVL 5402 engine. The trend of combustion process was similar, and we could recognize that AVL 5402 engine had shorter ignition delay and longer combustion duration. The longer combustion process generated higher combustion temperature.

Heat release rate of RCCI_1 engine was 60.5 $\mathrm{J} / \mathrm{deg}$, while it was $50 \mathrm{~J} / \mathrm{deg}$ in AVL 5402 engine. This result implied that the combustion process of RCCI_1 engine was better than that of AVL 5402 engine. In addition, the inclination of RCCI_1 engine was sharper than that of AVL 5402 engine. 


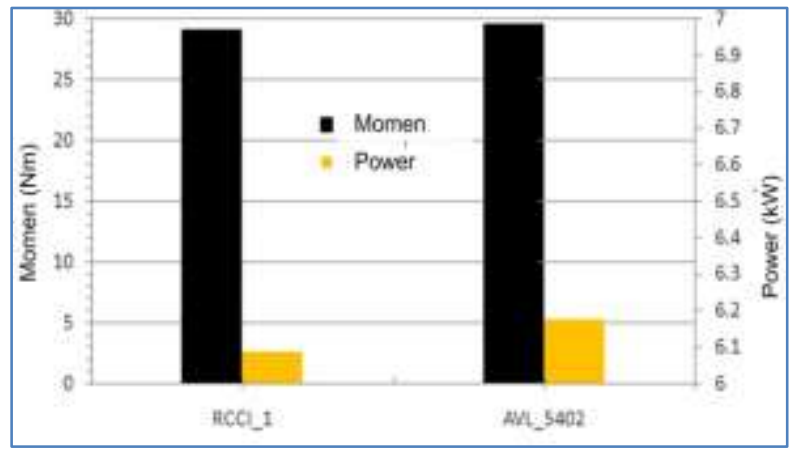

Fig-6: Power, moment of RCCI_1 and AVL 5402 engine

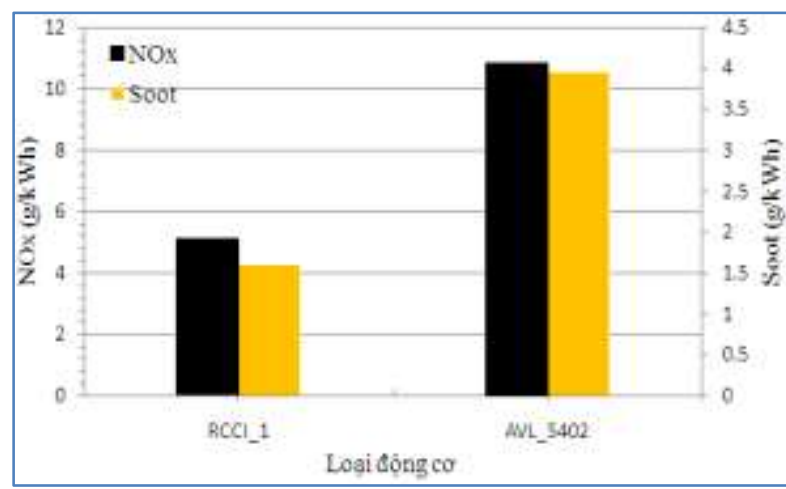

Fig-7: NOx and soot emission from RCCI_1 and AVL 5402 engine

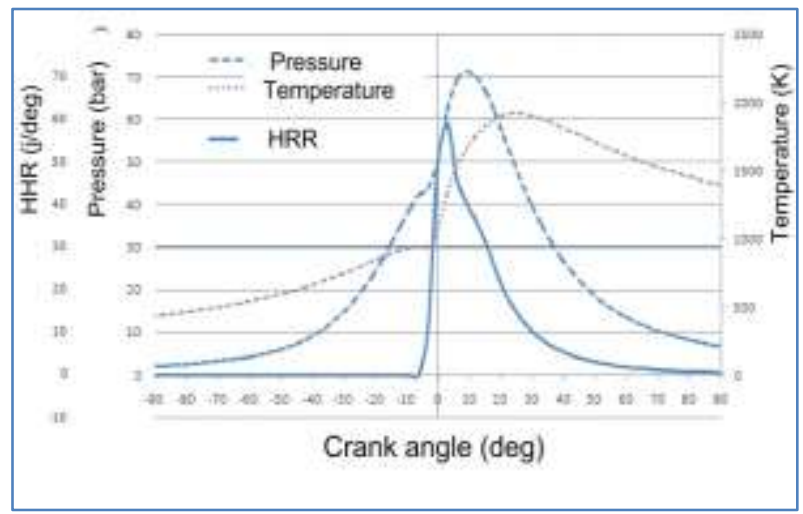

Fig-8: Pressure, temperature, and heat release rate curves of RCCI_1 engine

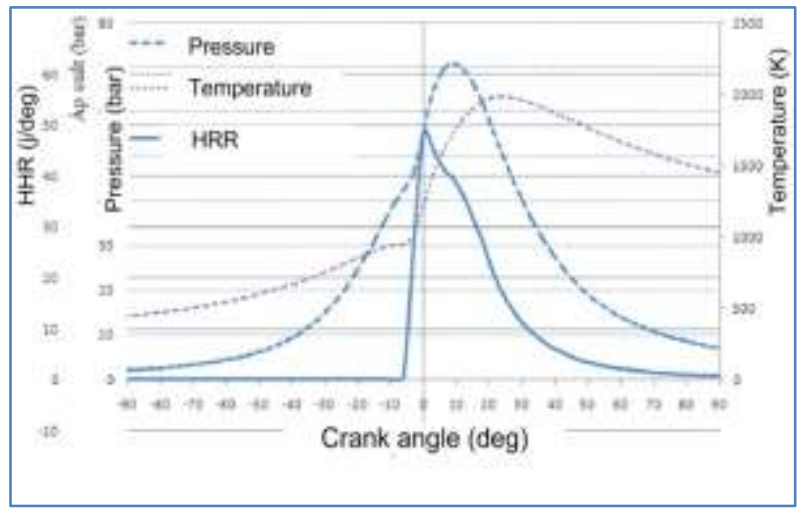

Fig-9: Pressure, temperature, and heat release rate curves AVL_5402 engine

\section{CONCLUSION}

The simulation study of RCCI gave us some promising results in developing new LTC concept engine. The RCCI engine demonstrated its advantages in comparison with convention direct-injection diesel engine. The RCCI engine generated high maximum pressure, fast in-cylinder pressure increase, and reducing late combustion period. The better combustion encouraged increasing engine power, momentum, and decreasing exhaust gas emissions.

In addition, tentative results in this research presented to us RCCI principle, which could be developed from simulation study. The simulation study should be conducted with other engine load and speed conditions to give a board picture of RCCI operation. By this investigation, we will design and manufacture the real RCCI engine for research in Vietnam.

\section{ACKNOWLEDGEMENTS}

The author would like to thank Mr. Dang Thai Son for his valuable time in discussing and supporting for the simulation.

\section{REFERENCES}

1. Y. Ali MA. Hanna, Alternative diesel fuels from ve getable oils. 1994: 153-163.

2. Abu-Jrai A, Tsolakis A, Theinnoi K, Cracknell R, Megaritis A, Wyszynski ML, Golunski SE. Effect of gas-to-liquid diesel fuels on combustion characte ristics, engine emissions, and exhaust gas fuel refor ming. Comparative study. Energy \& fuels. 2006 No v 15;20(6):2377-84.

3. Alleman TL, Eudy L, Miyasato M, Oshinuga A, Al lison S, Corcoran T, Chatterjee S, Jacobs T, Cherril lo RA, Clark R, Virrels I. Fuel property, emission t est, and operability results from a fleet of class 6 ve hicles operating on gas-to-liquid fuel and catalyzed diesel particle filters. SAE Technical Paper; 2004 Oct 25.

4. Das LM. Exhaust emission characterization of hydr ogen-operated engine system: nature of pollutants a nd their control techniques. International Journal of Hydrogen Energy. 1991 Jan 1;16(11):765-75.

5. IŞigigür A, Karaosmanoglu F, Aksoy HA, Hamdull ahpur F. Performance and emission characteristics of a diesel engine operating on safflower seed oil $\mathrm{m}$ ethyl ester. Applied biochemistry and biotechnolog y. 1994 Mar 1;45(1):93-102.

6. Al-Qurashi K, Boehman AL. Impact of exhaust gas recirculation (EGR) on the oxidative reactivity of $d$ iesel engine soot. Combustion and Flame. 2008 De c 1;155(4):675-95.

7. Demirbas MF, Balat M, Balat H. Potential contribu tion of biomass to the sustainable energy developm ent. Energy Conversion and Management. $2009 \mathrm{Jul}$ 1;50(7):1746-60.

8. Pearlman H. Low-temperature oxidation reactions and cool flames at earth and reduced gravity. 2000.

9. Perego C, Bortolo R, Zennaro R. Gas to liquids tec 
hnologies for natural gas reserves valorization: The Eni experience. Catalysis Today. 2009 Apr 15;142( 1-2):9-16.

10. Akansu SO, Dulger Z, Kahraman N, Veziroğlu TN. Internal combustion engines fueled by natural gas -hydrogen mixtures. International journal of hydr ogen energy. 2004 Nov 1;29(14):1527-39.

11. Ganesh D, Nagarajan G, Ibrahim MM. Study of per formance, combustion and emission characteristics of diesel homogeneous charge compression ignitio n (HCCI) combustion with external mixture format ion. Fuel. 2008 Dec 1;87(17-18):3497-503.

12. Kitamura Y, Kee SS, Mohammadi A, Ishiyama T, Shioji M. Study on NOx Control in Direct-Injectio n PCCI Combustion-Fundamental Investigation Us ing a Constant-Volume Vessel. SAE Transactions. 2006 Jan 1:358-67.

13. Espinoza RL, Steynberg AP, Jager B, Vosloo AC. Low temperature Fischer-Tropsch synthesis from a Sasol perspective. Applied Catalysis A: General. 1 999 Oct 4;186(1-2):13-26.

14. Shi L, Cui Y, Deng K, Peng H, Chen Y. Study of lo $\mathrm{W}$ emission homogeneous charge compression ignit ion (HCCI) engine using combined internal and ext ernal exhaust gas recirculation (EGR). Energy. 200 6 Nov 1;31(14):2665-76.

15. Komninos NP. Modeling HCCI combustion: Modif ication of a multi-zone model and comparison to ex perimental results at varying boost pressure. Applie d energy. 2009 Oct 1;86(10):2141-51. 